\title{
Análise dos impactos da seca no município de Sousa/PB
}

As secas que o Nordeste enfrenta vêm sendo monitoradas ao longo dos anos com a finalidade de compreender e se programar para lidar com as eventualidades que o clima proporciona. Sendo assim, o presente estudo tem como objetivo determinar e analisar os impactos causados pela seca, de 2012 a 2017 , utilizando um período de tempo subsequente (2018 e 2019) tendo o ano de 2008 como referência em virtude de sua característica chuvosa elevada, no município de Sousa-PB. Os dados utilizados foram fornecidos pelo USGS e IBGE e foram processados no software livre Qgis 2.14. Foram geradas espacializações multitemporais da área de estudo pelo uso de ocupação do solo e os índices de sensoriamento remoto (NDVI, TST e WSVI) no ano de referência e na época pós-seca para assim visualizar e caracterizar as alterações ocorridas no município de Sousa. Concluiu-se que a seca modificou o território e que de uma forma direta impactou o meio ambiente, seja por redução dos reservatórios causados pela escassez hídrica ou pela ocorrência de incêndio florestal favorecida pela vegetação seca, baixa condição hídrica e de umidade no solo. Isso ressoou na produtividade agrícola municipal e, por conseguinte na esfera social, decorrentes de impactos sobre a economia local, já que os agricultores tiveram produções limitadas, a zona urbana também sofreu impactos, pois foi submetida a racionamentos de água que afetaram diretamente os habitantes que residem no município.

Palavras-chave: Seca; Geoprocessamento; Uso e ocupação do solo.

\section{Analysis of the drought impacts in the city of Sousa/PB}

The droughts facing the Northeast have been monitored over the years in order to understand and plan to deal with the eventualities that the climate provides. Therefore, the present study aims to determine and analyze the impacts caused by drought, from 2012 to 2017, using a subsequent period of time (2018 and 2019) with the year 2008 as a reference due to its high rainy characteristic, in the municipality of Sousa-PB. The data used were provided by the USGS and IBGE and were processed using the free software Qgis 2.14. Multitemporal spatialization of the study area was generated by the use of land occupation and the remote sensing indexes (NDVI, LST and WSVI) in the reference year and in the post-dry season to visualize and characterize the changes that occurred in the municipality of Sousa. It was concluded that the drought modified the territory and that in a direct way it impacted the environment, either by reducing the reservoirs caused by water scarcity or by the occurrence of forest fire favored by dry vegetation, low water condition and soil moisture. This resonated with municipal agricultural productivity and, therefore, in the social sphere, resulting from impacts on the local economy, since farmers had limited production, the urban area also suffered impacts, as it was submitted to water rationing that directly affected the inhabitants that live in the municipality.

Keywords: Drought; Geoprocessing; Land use and occupation.

Topic: Engenharia Ambiental

Reviewed anonymously in the process of blind peer
Received: 03/01/2021

Approved: 28/01/2021
José Diogenes Alves Pereira (iD

Universidade Federal de Campina Grande, Brasil

http://lattes.cnpq.br/0794148901792036

http://orcid.org/0000-0002-8160-4126

diogenes753@hotmail.com

Virgínia de Fátima Bezerra Nogueira (iD

Universidade Federal de Campina Grande, Brasil

http://lattes.cnpq.br/8421288987001547

http://orcid.org/0000-0002-5564-1011

virginia.fbnogueira@gmail.com

Valner da Silva Nogueira (ib

Universidade Federal de Campina Grande, Brasil

http://lattes.cnpq.br/4474604318020386

http://orcid.org/0000-0001-7011-2284

nvalner@hotmail.com

\author{
Andréa Karla Gouveia Cavalcanti ic \\ Universidade Federal de Campina Grande, Brasil \\ http://lattes.cnpq.br/2784148914137982 \\ http://orcid.org/0000-0002-5151-9270 \\ andreakgcavalcanti@gmail.com \\ Francisco Jean da Silva Paiva (iD \\ Universidade Federal de Campina Grande, Brasil \\ http://lattes.cnpq.br/0767430146380526 \\ http://orcid.org/0000-0001-7603-4782 \\ je.an93@hotmail.com
}

Referencing this:

PEREIRA, J. D. A.; NOGUEIRA, V. F. B.; NOGUEIRA, V. S.; CAVALCANTI, A. K. G.; PAIVA, F. J. S.. Análise dos impactos da seca no município de Sousa/PB. Revista Ibero Americana de Ciências Ambientais, v.12, n.1, p.335-346, 2021. DOI: http://doi.org/10.6008/CBPC21796858.2021.001.0028 


\section{INTRODUÇÃO}

O Brasil é um país de dimensões continentais e possui uma grande variabilidade climática e diversidades fisiográficas. Segundo Marengo (2010), a Região Nordeste do Brasil detém $1.600 .000 \mathrm{~km}^{2}$ do território nacional e cerca de $62 \%$ de sua área se encontra dentro do Polígono das Secas, que implica em menores índices pluviométricos característicos do clima semiárido. Vários municípios do Nordeste se encontram em condições adversas, com falta de água e tendo ocorrências de chuvas abaixo dos 800mm anuais. O clima semiárido se encontra espalhado por cerca de $86 \%$ da área da região nordeste onde vivem 30 milhões de pessoas aproximadamente, o que corresponde a $15 \%$ da população brasileira, sendo, portanto, a região seca mais habitada do mundo (MARENGO, 2010).

As secas que o Nordeste enfrenta vêm sendo foco de muitos estudos ao longo dos anos que visam compreender e se programar para lidar com as eventualidades que o clima proporciona em cima destes pontos, com muitas relatividades, que derivam desde efeitos econômicos a mortalidade de pessoas se observada pela seca de 1777 que ocasionou a morte de milhares de nordestinos, afetando também a agricultura e a pecuária de subsistência (CAMPOS et al., 2001).

Como fenômeno natural a seca é considerada um evento severo, de intensas influências que resultam em danos materiais e humanos, ao ponto de serem chamados de desastres ambientais e sociais, causando prejuízos socioeconômicos. Um dos principais fatores de risco na linha semiárida está ligado também a infraestrutura, que em sua ausência propicia a intensificação dos impactos causados pela seca (SILVA et al., 2013).

Por outro lado, os efeitos atingem diretamente as produções agrícolas que resultam em significativas quedas de produtividade em suas culturas e que em algumas regiões chega a diminuir cerca de 30 por cento do potencial produtivo devido às limitações que as secas impõem, em outros cenários ocorrem percas totais de suas produtividades, o que resulta em efeitos na sociedade, os quais alteram a configuração dos municípios e até os perfis culturais de determinadas regiões (CAVALCANTI et al., 1996).

Neste contexto são perceptíveis como às vulnerabilidades sociais estão ligadas aos efeitos da seca, onde seu monitoramento é baseado em estudos que proporcionam o entendimento necessário e possibilita antever e lidar com os impactos que ocorrem ou que podem ocorrer na vida das populações dos municípios atingidos (NYS et al., 2016).

No século XX se inaugurou uma nova forma de gerir cenários de seca a qual o governo combatia as eventualidades com base em comissões, que com o tempo foram encerradas por não terem desempenhos satisfatórios. Com os avanços na gestão de recursos hídricos foi focado em pontos realmente relevantes e essenciais e estes aprimoramentos foram os formadores do atual Departamento de Obras Contra as Secas DNOCS (SUASSUNA, 2007).

Ultimamente para se detectar a seca e a sua severidade são utilizados índices o para monitoramento, baseados em variáveis como temperatura, evaporação, precipitação, umidade no solo, vazão e evapotranspiração. A geração e utilização desses índices de forma apropriada dependem do esforço 
coordenado de diversos indivíduos, instituições e sistemas de dados, que em conjunto expressam a realidade. Tais informações são importantes para a geração de estudos e aplicabilidade deles na gestão e preparação para mitigar os efeitos das secas (NYS et al., 2016).

Seja a seca tratada como um problema ou uma eventualidade climática é necessário conhecer e monitorar esse fenômeno para que sejam tomadas ações devidas, que podem vir a contribuir para a salva guarda das populações não somente do Nordeste, mas do planeta, que se encontram sujeitos às condições que a seca impõe (CAMPOS et al., 2001).

O presente trabalho busca analisar os impactos causados pela seca severa que perdurou por quase seis anos consecutivos, de 2012 a 2017, na cidade de Sousa usando um ano chuvoso como referência (2008), e determinar como essa seca interferiu no município, usando o geoprocessamento para analisar e caracterizar o uso e ocupação do solo dos anos subsequentes à seca e determinar os impactos.

\section{METODOLOGIA}

O município de Sousa localizado no interior do estado da Paraíba possui, segundo o IBGE (2010), uma densidade demográfica de $89,10 \mathrm{hab} / \mathrm{km}^{2}$ e uma população estimada em 69,444 habitantes e uma unidade territorial de 738,54 km². Detentor do bioma Caatinga, na Figura 1 encontra-se o mapa de localização da área de estudo.

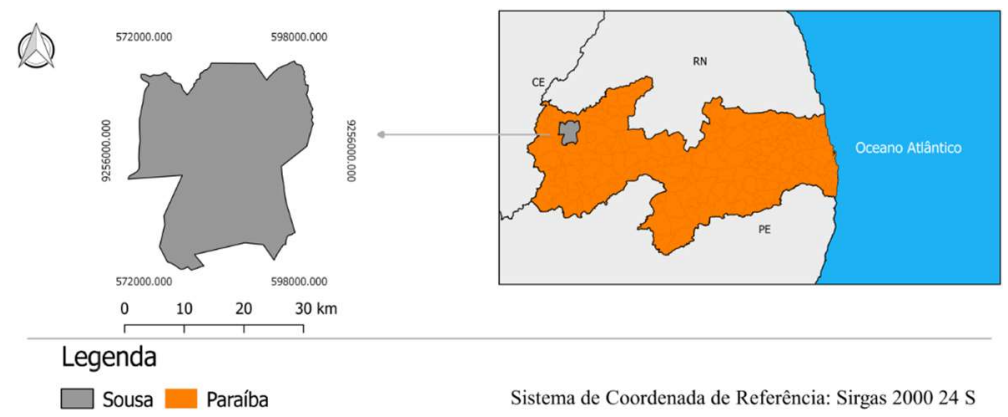

Figura 1: Mapa de localização do município de Sousa no estado da Paraíba. Fonte: Dados fornecidos pelo IBGE (2015).

Ainda compreendendo o território, o município possui uma referida produção agrícola de seletas culturas a exemplo do plantio de coco que com o passar dos anos sofreram tanto quanto as secas prolongadas como a salinização dos solos.

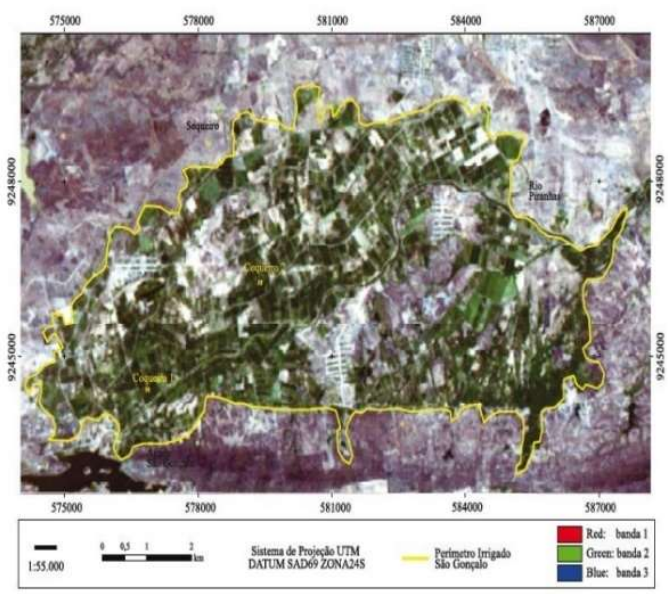

Figura 2: Perímetro irrigado de São Gonçalo, Sousa, Paraíba. Fonte: Silva et al. (2012). 
Na Figura 2, está plotado o perímetro irrigado de São Gonçalo no dia 01 de novembro de 2008, a qual a imagem detém sua data de captação no mesmo mês que o ano base do presente estudo, ano está referência por ter detido elevadas precipitações.

Esta área irrigada é significativa para o estudo devido às produções na área ocorrerem com base na irrigação, onde as águas que abastecem as culturas locais são provenientes do Açude de São Gonçalo que se localiza parcialmente dentro do município de Sousa-PB.

Para o processamento digital de imagens foi utilizado o software livre Qgis 2.14 para o processamento das imagens do satélite LandSat 5 do dia 17 de novembro de 2008 e LandSat 8 do dia 15 de dezembro de 2018 e do dia 16 de novembro de 2019 a qual os satélites capturaram a imagem nos respectivos horários de 12:24:47, 12:41:19 e 12:41:46. Estas imagens foram processadas e por meio da classificação de imagens realizada pelo PluginSPC - Semi-automatic Classification Plugin presente no Qgis foram gerados três mapas de uso e ocupação do solo do município de Sousa nos anos de 2008, 2018 e 2019, para visualizar como a seca incidiu sobre o território, estes mapas compreendem as seguintes classes: No ano de 2008 e 2018, foram analisados: Área urbana; Vegetação úmida; Vegetação seca; Solo exposto e Corpos hídricos. Já para o ano de 2019, foram analisados; Área urbana; Vegetação úmida; Vegetação seca; Solo exposto; Corpos hídricos e, Focos de Calor.

Respectivamente a cada mapa de uso e ocupação do solo foram gerados gráficos que indicam as porcentagens de cada uso citado acima nos referidos anos para que fossem analisadas as frações percentuais em relação aos mapas. Utilizando o Google Earth Pro foi gerada uma imagem que evidência uma área incendiada no ano de 2019 para fins de controle com o mapa de uso e ocupação do solo no ano de 2019.

Foi calculado o índice NVDI, em mesma escala, nos anos de 2008, 2018 e 2019, com finalidade de identificar a variabilidade espacial da vegetação presente no território municipal de Sousa.

O NDVI é calculado com base na refletividade medida nas bandas NIR que é o infravermelho próximo de comprimento de onda (0,75-0,90 um) e R que é o vermelho de comprimento de onda (0,63-7 um) este índice tem como equação de número 1.

$$
N D V I=\frac{(N I R-R)}{(N I R+R)}
$$

Foram criados três mapas em mesma escala que indicam o índice TST nos mesmos anos citados com a finalidade de compreender possíveis mudanças térmicas naquela área nos referidos anos.

A estimativa da temperatura da superfície terrestre foi determinada a partir de dados de diversos sensores como no LandSat 5 a qual convertendo os números digitais (DN), para valores de TST utilizando a banda termal número 6 é possível tornar valores comparáveis entendendo que $L \lambda$ é a radiação de energia espectral(Watts/( $\mathrm{m}^{2}$.sr.um)), Lmin é a radiância espectral de $\mathrm{DN}$ igual a $1 \mathrm{Lmax}$ é a radiância espectral de DN igual a 255 e DN é o número digital, essa conversão se dá inicialmente pela equação 2.

$$
L \lambda=\operatorname{Lmin}+\frac{(\operatorname{Lmax}-L \min ) * D N}{255}
$$

Com o valor obtido o passo posterior foi a substituição desse valor de $L \lambda$ na equação abaixo que 
determina a temperatura da superfície terrestre com base nas variáveis, a qual K 1 é a constante de calibração (607,76K), K K é a constante de calibração (1260,56K) e Tb é o valor estimado da temperatura da superfície terrestre a qual deve ser subtraída por 273 para converter de graus Kelvin para Celsius onde Tb é denotado pela equação 3 .

$$
T b=\frac{K 2}{\ln \left(\frac{K 1}{L \lambda}\right)+1}
$$

Utilizando imagens LandSat 7 e 8 o processamento realizado foi o de Coelho e Correa (2013) foi utilizado como base na banda espectral termal de número 10 que corresponde a faixa de infravermelho termal do comprimento de onda (10.6-11.19 um) que parametriza e é comparada a temperatura do sensor de registro.

A estimativa da temperatura da superfície terrestre com imagens LandSat 8 é concretizada pelo uso inicial das variáveis, $L \lambda$ que é a radiância espectral do sensor, $M_{L}$ que é o fator multiplicativo de redimensionamento da banda 10 de valor (3.3420E-04), A é o fator de redimensionamento aditivo específico da banda 10 de valor (0.1) e Qcal é o valor quantizado de calibração do pixel em DN também em relação a banda 10. Está conversão de número digital é dada pela equação 4.

$$
L \lambda=M L * Q c a l+A L
$$

Com a transformação realizada pela equação 4 aplica-se o valor de $L \lambda$ na equação 5 que possui as variáveis T que é a temperatura efetiva, $K_{2}$ que denota a constante de calibração dois (1.321.08K), K1 é a constante de calibração um (774.89K) e $L \lambda$ é a radiância espectral (Watts/( $\mathrm{m}^{2}$.sr.um)) como visto na equação 5 que se encontra abaixo:

$$
T b=\frac{K 2}{\ln \left(\frac{K 1}{L \lambda}\right)+1}
$$

\section{IMAGENS DOS SATÉLITES LANDSAT}

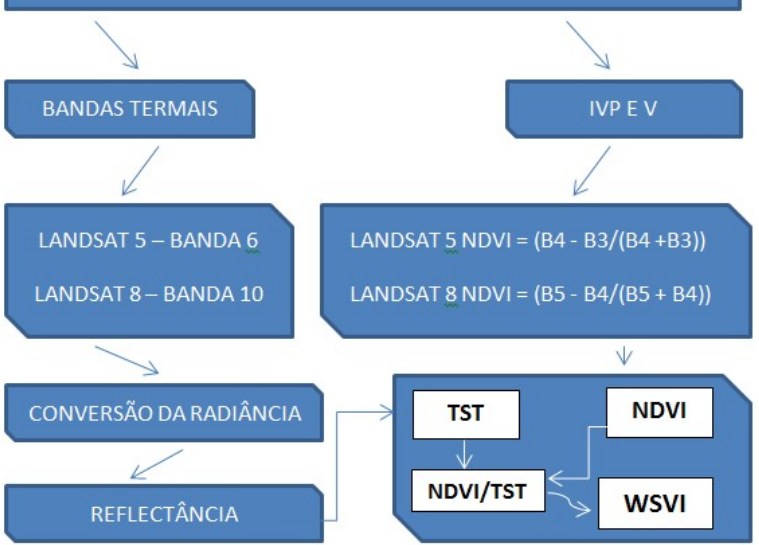

Figura 3: Fluxograma do processo metodológico para obtenção dos índices. Fonte: Alshaikh (2015).

Por sequência foram gerados três mapas de WSVI para que assim fosse possível interpretar como se deu as transformações de umidade nas vegetações dentro do município dos respectivos anos anteriormente citados. O WSVI foi calculado pela equação que utiliza o NDVI e o TST anteriormente determinados, na qual a razão abaixo presente na equação 6 descrita abaixo: 


$$
W S V I=\frac{N D V I}{T S T}
$$

Com base no procedimento metodológico anterior, segue abaixo na Figura 3 os passos sintetizados e realizados para a determinação do NDVI, TST e WSVI dos anos de 2008, 2018 e 2019 para assim acompanhar as informações destes índices observando os efeitos após a seca que afetou o município de Sousa. Utilizando o ano de 2008 como base para a visualização das alterações pós seca nos anos de 2018 e 2019.

\section{RESULTADOS E DISCUSSÃO}

Na Figura 4 observa-se a distribuição da ocupação do solo nos três anos analisados. No mapa a zona urbana se encontra ao centro do município e como em 2008 choveu bem, expressa algumas áreas de vegetação úmidas, na tonalidade de verde, que se encontram próximos aos corpos hídricos, onde o Perímetro Irrigado de São Gonçalo é expresso por uma grande mancha verde. Poucas parcelas de solo exposto são visíveis no mapa, já a Caatinga com sua vegetação seca possui uma vasta ocupação territorial.

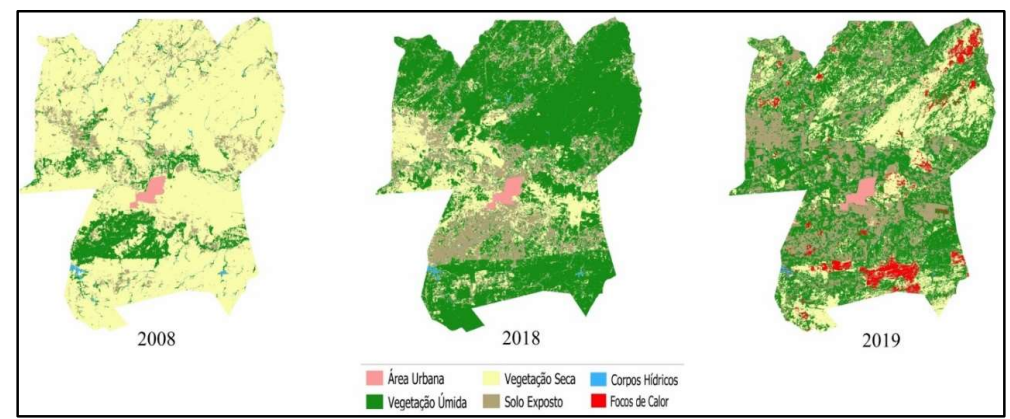

Figura 4: Mapas de uso e ocupação do solo do município de Sousa-PB em 2008, 2018 e 2019. Fonte: Dados fornecidos pelo USGS 2008, 2018, 2019 e IGBE (2015).

Na Figura 4, a imagem do dia 15 de dezembro de 2018, nota-se que o município teve transformações consideráveis do ponto de vista do uso e ocupação do solo. Na qual a quantidade de vegetação úmida ocupa uma grande área dentro do limite do município, tal efeito se deu por um considerável número de dias com chuvas que ocorreram do dia 1 ao dia 14 de dezembro, choveu 128,4mm segundo dados do DNOCS.

Quanto ao perímetro irrigado, é visto um declínio das produções e em suas áreas se encontram parcelas de solo exposto. No estudo de Siqueira (2017), ele concluiu que no período de 2012 a 2016 se teve consideráveis perdas de produção no perímetro irrigado, que causou vários transtornos financeiros que dificultaram a vida das famílias que dependiam daquelas práticas agrícolas. Essa diminuição na produtividade das culturas também se deve ao fato da irrigação mal planejada que propiciou uma acentuada salinização do solo.

Ainda sobre a Figura 4 tem-se a imagem captada em 16 de novembro de 2019, evidenciando informações que expressam efeitos característicos de um período pós-seca, além dos corpos hídricos apresentarem uma menor quantidade de área ocupada se comparado ao ano base. Segundo dados do DNOCS, a última chuva registrada antes do dia 16 /novembro foi de $4,2 \mathrm{~mm}$ ocorrida no mês de agosto. Neste cenário é justificável a quantidade de focos de calor presentes no mapa e como eles ocorreram em locais próximos a vegetações secas. 
Na Figura 5 encontram-se as áreas estimadas dos mapas da Figura 4 dos anos de 2008, 2018 e 2019 respectivamente. A vegetação seca estava abrangendo quase $80 \%$ do território devido à imagem de satélite ser do dia 17 de novembro de 2008, 46 dias após a ocorrência de uma chuva de 5.6mm, segundo dados do INMET.

Quanto às áreas ocupadas, no ano de 2019, o gráfico expressa tantos os focos de calor quanto às demais áreas analisadas. A vegetação úmida ocupa mais de $46 \%$ do espaço municipal, o que aponta que possivelmente se teve índices pluviométricos que permitiram que a vegetação se mantivesse nessa condição, mesmo estando no período seco, também se tem uma considerável parcela de vegetação seca (24,86\%) essa que naturalmente ou criminosamente fica mais vulnerável a ocorrência de incêndios.

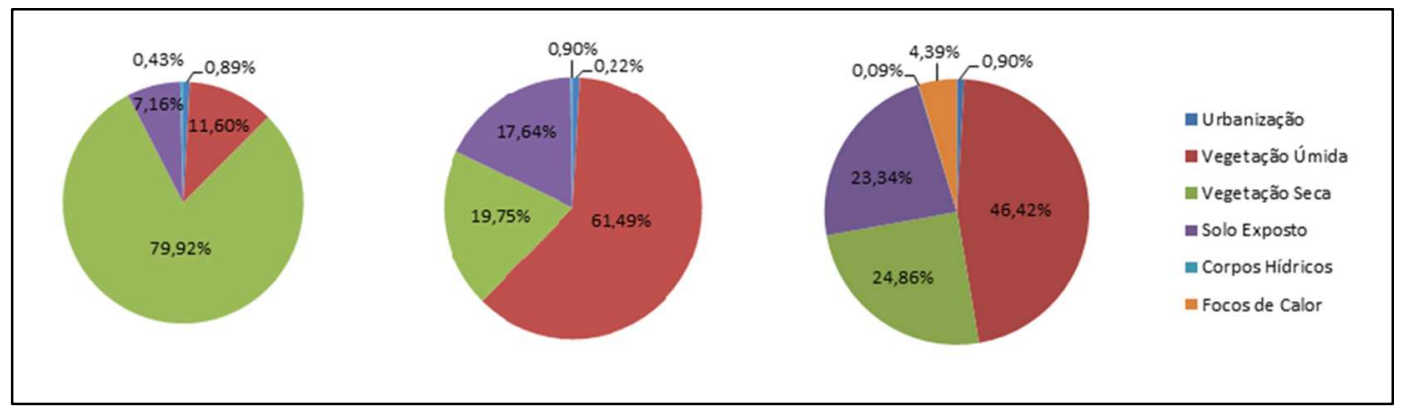

Figura 5: Áreas ocupadas no município de Sousa-PB em 2008, 2018 e 2019. Fonte: Dados fornecidos pelo USGS 2008, 2018, 2019 e IGBE (2015).

Em consulta ao corpo de bombeiros de Sousa, que cederam os dados de incêndios nas vegetações, os mesmos focos de calor observados em Sousa também ocorreram nas áreas circunvizinhas de Sousa, no sertão Paraibano, por possuírem condições similares de vegetação e clima. Na Tabela 1 estão a quantidade de incêndios registrados.

É notável como no período seco do ano a vegetação da Caatinga fica muito seca, mesmo em um ano que apresentou um período chuvoso normal, mas por ser um ano pós-seca a ocorrência de incêndios foi alta. Dentro do limite municipal de Sousa pela análise espacial, se teve um número considerável de áreas atingidas pelos incêndios, bem como em outros municípios próximos.

Tabela 1: Incêndios florestais registrados pelo corpo e bombeiros de Sousa-PB em 2019.

\begin{tabular}{lll}
\hline Natureza da Ocorrência & Mês & Quantidade \\
\hline Incêndio na Vegetação & Setembro & 28 \\
Incêndio na Vegetação & Outubro & 21 \\
Incêndio na Vegetação & Novembro & 18 \\
Incêndio na Vegetação & Dezembro & 14 \\
\hline
\end{tabular}

Fonte: Corpo de Bombeiros Militar - 6ㅇ Batalhão Bombeiro Militar.

Os focos de calor tiveram 4,39\% de ocupação de área que em análise é superior à zona urbana de Sousa $(0,90 \%)$, ou seja, os focos de calor somados eram quatro vezes maior que a área da cidade de Sousa.

Na Figura 6 pode-se observar os focos de calor presentes na imagem de satélite. Nela é possível visualizar como as vegetações secas propiciam o alastramento do fogo, onde é possível contrastar vegetações úmidas pelos tons de verde mais escuro e vegetações secas com os tons mais marrons.

Analisando o NDVI do ano base, na Figura 7, é notável em 2008, como os corpos hídricos (-0,154) são 
expressivos, pois foi um ano chuvoso, percebe-se uma elevada quantidade de pequenos lagos dentro do território que juntamente com o açude de São Gonçalo e o Rio do Peixe. Essas áreas condicionavam vegetações ciliares, e a expressiva produtividade agrícola, onde a áreas vegetadas apresentam valores de 0,722 de NDVI.

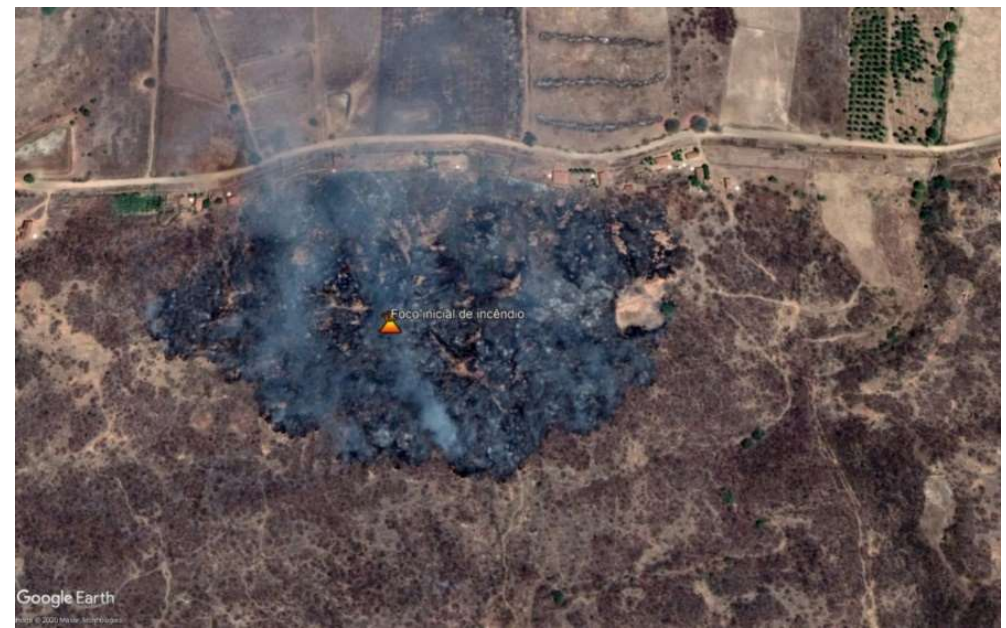

Figura 6: Recorte de um dos focos de incêndio em 2019. Fonte: Google Earth Pro (2019).

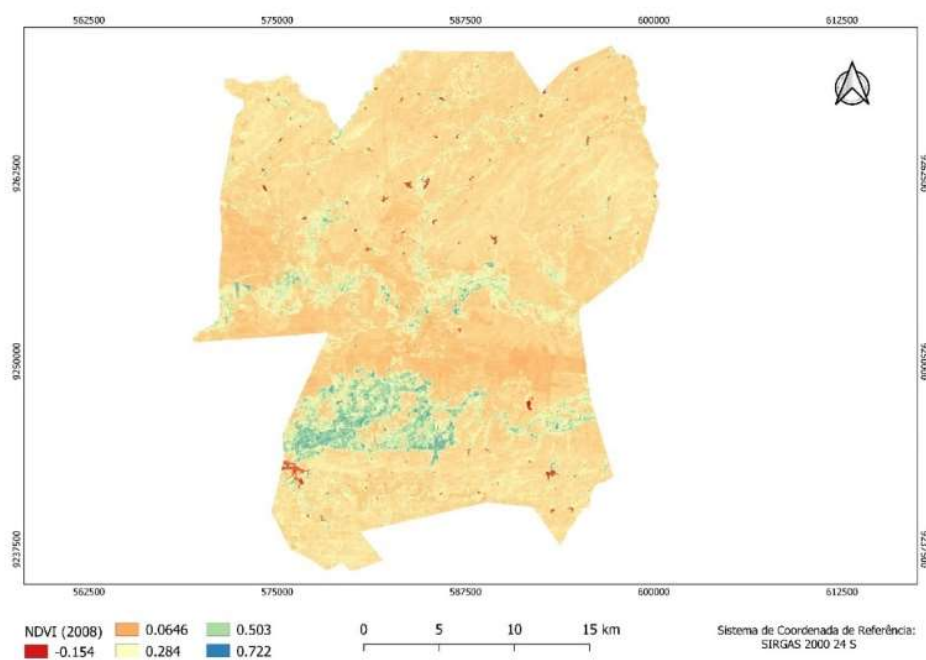

Figura 7: NDVI do município de Sousa-PB em 2008. Fonte: Dados fornecidos pelo USGS 2008 e IGBE (2015).

Na Figura 8 observa-se o mapa com o NDVI, imagem de satélite do dia 15 e dezembro de 2018, percebe-se que as precipitações ocorridas do dia 1 ao dia 14 de dezembro acumularam 128,4mm segundo dados do DNOCS, alteraram morfologia da área, expressando assim a resiliência da vegetação da Caatinga, apresentando valores elevados de NDVI para um período pós-seca. A Caatinga é extremamente sensível à precipitação e como choveu muitos poucos dias antes da captura da imagem, a vegetação ficou verde e os valores de NDVI foram elevados.

Quanto aos corpos hídricos é notória a mudança em relação ao ano de 2008 , devido à diminuição acentuada dos pequenos lagos e do açude que abastece o município.

Em 2019, o NDVI apresentou uma condição mais condizente com um período pós-seca, Figura 9, na qual as áreas mais vegetadas são as com o perfil de ciliaridade e, como as irrigações diminuíram consideravelmente o volume dos corpos hídricos foi inferior ao observado em 2008. 


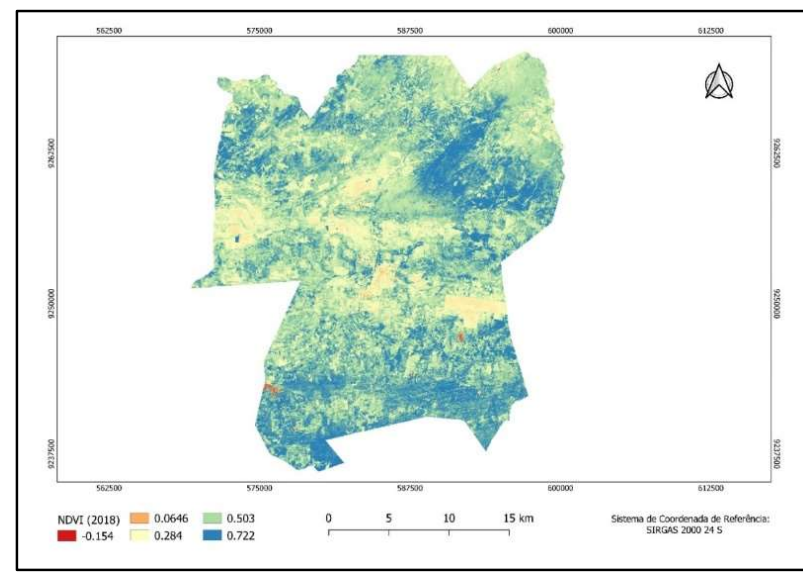

Figura 8: NDVI do município de Sousa-PB em 2018. Fonte: Dados fornecidos pelo USGS 2018 e IGBE (2015).

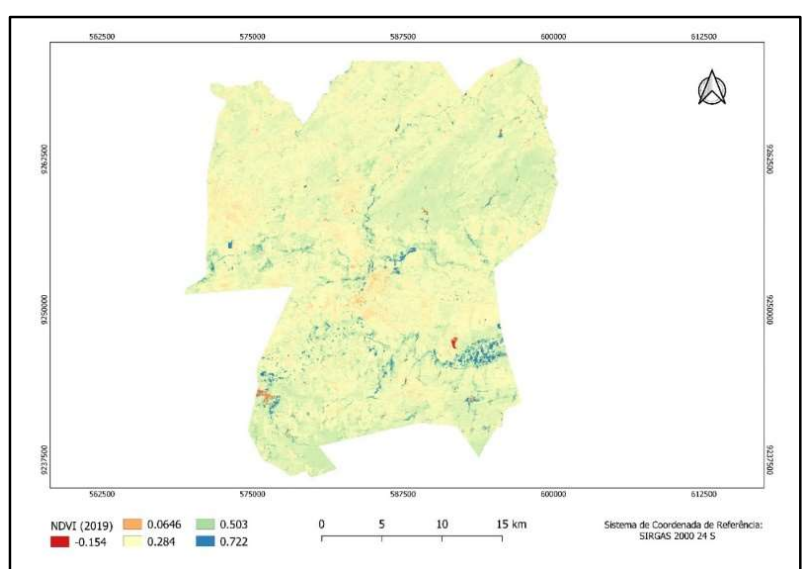

Figura 9: NDVI do município de Sousa-PB em 2019. Fonte: Dados fornecidos pelo USGS 2019 e IGBE (2015).

A Temperatura da Superfície Terrestre (TST) é influenciada pelos elementos climatológicos e também pelo relevo, a presença e ausência de vegetações. Na Figura 10 observa-se a TST do ano de referência.

As temperaturas do perímetro irrigado se destacaram em relação às outras vegetações, bem como pequenas porções dentro da área que possivelmente são pequenos lagos e áreas produtivas irrigadas expressadas pelos tons de azul e verde inferiores a $34,42^{\circ} \mathrm{C}$.

No mapa é visível como a maioria do território possui temperaturas superiores a 39,63 ㄷ e que também inúmeras porções apresentam temperaturas maiores que 44,85 ㄷ C.

Na Figura 11 estão as TST em 2018 que foram mais baixas devido às precipitações que ocorreram antes do dia da passagem do satélite e isso afetou nas temperaturas da superfície. Essa diferença em relação ao ano de 2008 é visível, nos corpos hídricos estão registradas as menores temperaturas, e as áreas vegetadas que se encontravam úmidas apresentam temperaturas pouco acima das mais baixas registradas, abrangendo uma significativa parcela do terreno.

Nesta imagem se tem uma menor concentração de locais com temperaturas acima dos $39,63^{\circ} \mathrm{C}$ e porções ainda menores com temperaturas acima de $44,85^{\circ} \mathrm{C}$.

Sem precipitações atenuadoras das temperaturas da superfície está o mapa de TST do ano de 2019 na Figura 12. Neste ano é incontestável a forma que as temperaturas se distribuíram no terreno, na maioria das áreas as temperaturas foram superiores a 44,85ㄷ․ Nos corpos hídricos remanescentes do período pósseca se tem as menores temperaturas de $23,98^{\circ} \mathrm{C}$, já os cursos dos rios apresentam temperaturas mais elevadas na faixa de 34,42 a 39,63 드, tal efeito pode ser justificado pela ausência de água nos cursos d'água devido aos rios não serem perenes.

Na Figura 13, o WSVI indica uma variabilidade de umidades nas vegetações dentro da área analisada, na qual de forma nítida percebe-se que as zonas irrigadas e ciliares se encontram com maior umidade em suas vegetações por isso os valores superiores a 0,0273.

As lâminas d'água apresentam valores negativos destacados pela cor vermelha, já a maior parte do território possuindo valores 0,0028 a 0,011 expressos pela cor laranja, que ressalta a vegetação seca da Caatinga com umidades inferiores ao perímetro irrigado de São Gonçalo e demais áreas ciliares. 


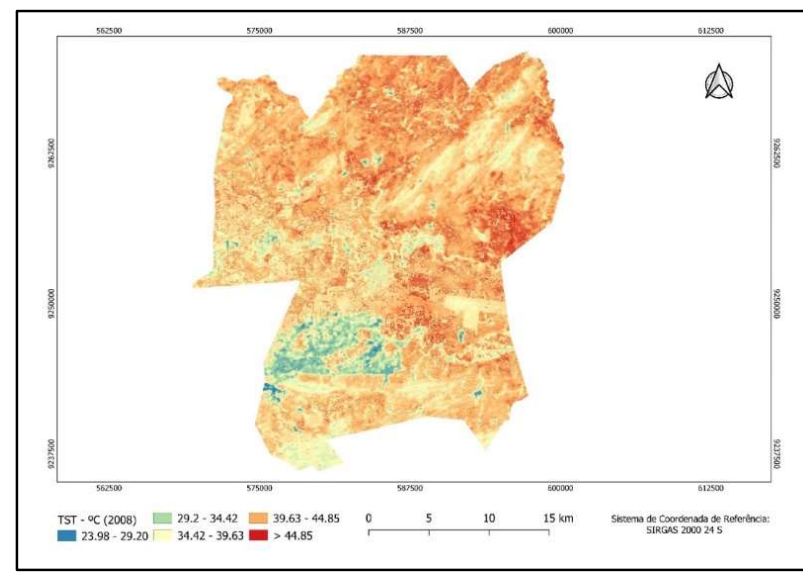

Figura 10: Mapa de TST do município de Sousa-PB em 2008. Fonte: Dados fornecidos pelo USGS 2008 e IGBE (2015).

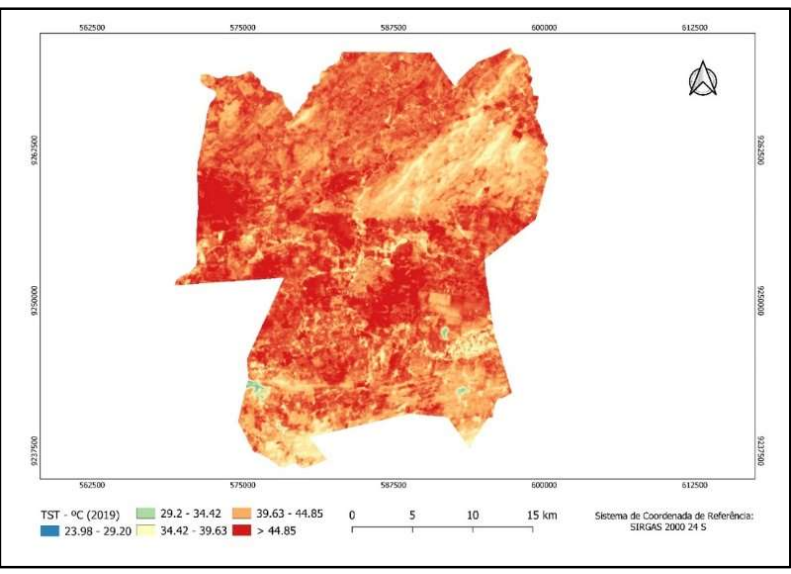

Figura 12: Mapa de TST do município de Sousa-PB em 2019. Fonte: Dados fornecidos pelo USGS 2019 e IGBE (2015).

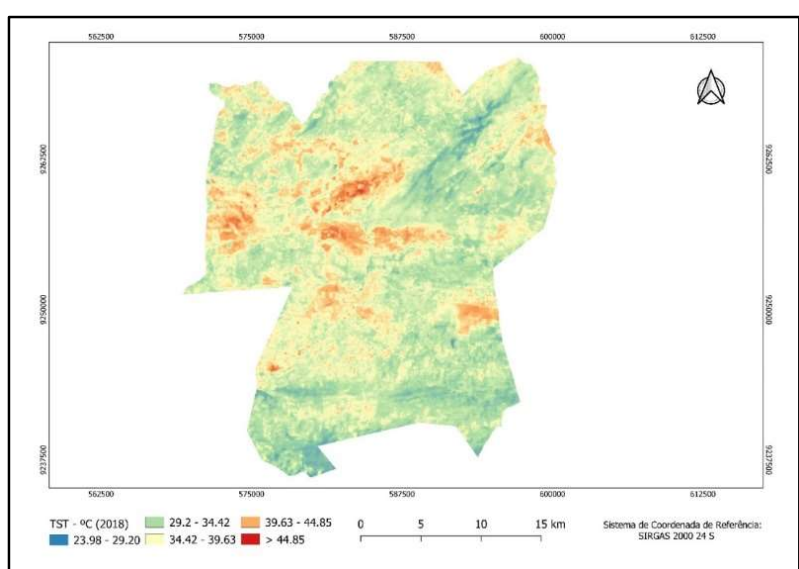

Figura 11: Mapa de TST do município de Sousa-PB em 2018. Fonte: Dados fornecidos pelo USGS 2018 e IGBE (2015).

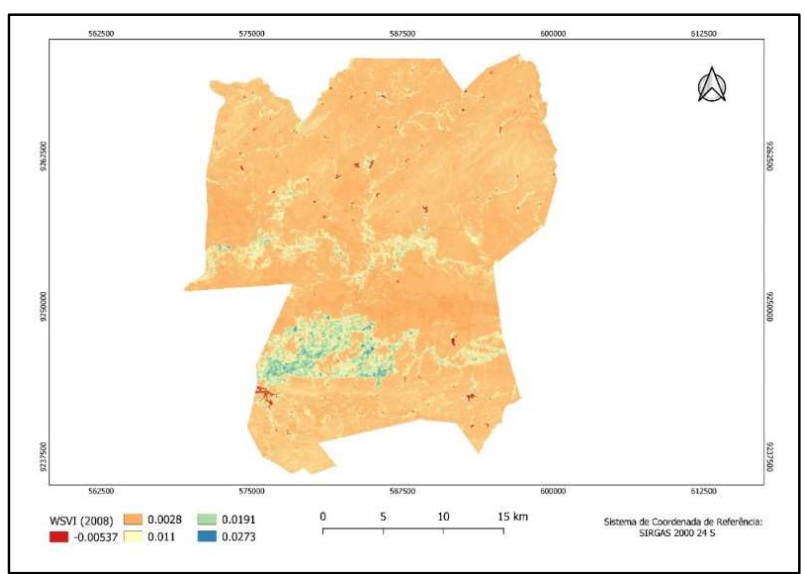

Figura 13: WSVI do município de Sousa-PB em 2008.

Fonte: Dados fornecidos pelo USGS 2008 e IGBE (2015).

No ano de 2018 o índice demonstrou, observado na Figura 14, que há umidade na vegetação especializada no mapa. Após o acumulado de chuvas de 128,4mm registradas do dia 1 ao dia 14 de dezembro e considerando a data da imagem de 15 de dezembro de 2018, todos os constituintes presentes no mapa apresentaram umidade e as vegetações em sua grande maioria detiveram valores maiores que 0,0191 com tom verde claro e azul, que cobriram grande parte da área analisada. Já as áreas de solo exposto e as vegetações de pequeno porte tiveram pouco armazenamento de umidade nas plantas e os valores de WSVI foram inferiores a 0,0028.

$\mathrm{Na}$ ausência de umidade a zona urbana se tornou mais visível e terrenos de grandes produtores agrícolas, além do perímetro irrigado, foram expostos, nas cores verde claro e azul com valores 0,0191 e 0,0273 , respectivamente.

Em 2019 as mutabilidades territoriais da umidade marcaram as seguintes informações observadas na Figura 15: A umidade na maioria das áreas vegetadas se encontrava muito baixa, está espacialidade observada possui valores entre 0,011 a 0,0273 que vão das cores amarela a laranja. Poucos são os pontos no mapa que detêm vegetações umidades superiores a 0,0191 (Figura 15). 


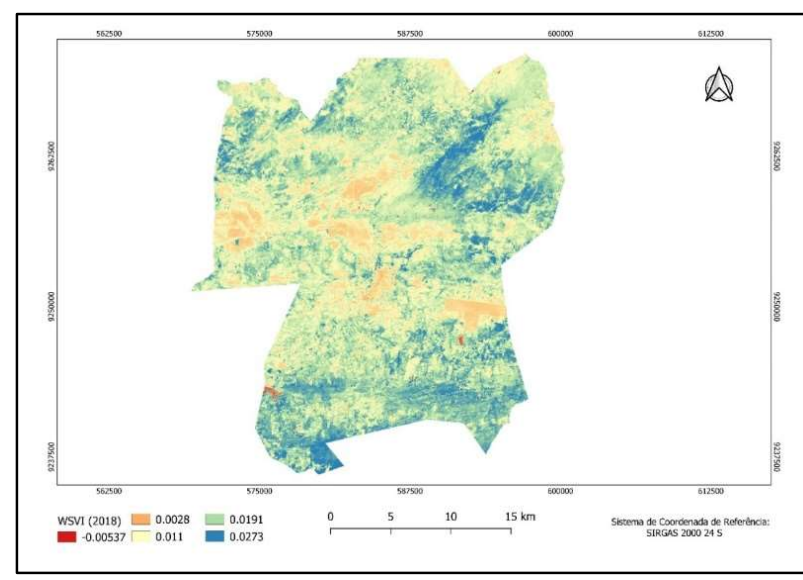

Figura 14: WSVI do município de Sousa-PB em 2018.

Fonte: Dados fornecidos pelo USGS 2018 e IGBE (2015).

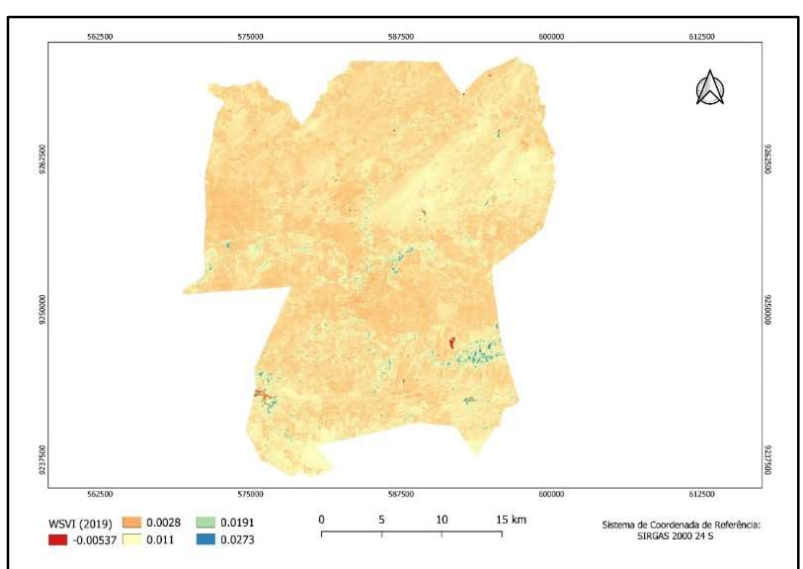

Figura 15: WSVI do município de Sousa-PB em 2019.

Fonte: Dados fornecidos pelo USGS 2019 e IGBE (2015).

\section{CONCLUSÕES}

Compreendendo objetivo proposto as transformações espaciais do município de Sousa apontaram significativos impactos no uso e ocupação do solo quando comparado com o ano de referência, 2008. 0 ano de 2008 foi um ano substancialmente chuvoso e comparando aos demais anos ficou nítida como a disponibilidade de recursos foi afetada pela seca ocorrida antes de 2018. Observou-se que os corpos hídricos nos anos pós-seca estavam com volume reduzido quando comparado há 10 anos, isso resultou em declínio na produção agrícola do perímetro irrigado de São Gonçalo. Em outra perspectiva, se tem os incêndios florestais que impactaram negativamente na fauna, flora e qualidade do ar.

A mutabilidade da localidade ficou bastante visível quando se analisou os índices. Com o NDVI observou-se a diminuição das áreas vegetadas, resultantes de intervenções antrópicas e/ou naturais. Porém, foi percebido como as precipitações são capazes de alterar a coloração da Caatinga, onde a vegetação responde rapidamente as chuvas ficando verde. O TST apontou que após a seca as temperaturas ainda se mantiveram altas principalmente em 2019. O índice WSVI, por ser mais sensível a condição de umidade na vegetação que o NDVI, comprovou que nos anos pós-seca a vegetação sofreram com a escassez hídrica de tal forma que o perfil agrícola produtivo municipal foi afetado negativamente.

\section{REFERÊNCIAS}

ALSHAIKH, A. Y.. Space applications for droughtassessment in Wadi-Dama (West Tabouk), KSA. The Egyptian Journal of Remote Sensing and Space Science, v.18, n.1, p.S43-S53, 2015.

CAMPOS, J. N. B.; STUDART, T. M. C.. Secas no Nordeste do Brasil: origens, causas e soluções. In: DIÁLOGO INTERAMERICANO DE GERENCIAMENTO DE ÁGUAS, 4. Anais. Foz do Iguaçu: ABRH, 2001.

CAVALCANTI, N. B.; RESENDE, G. M.; BRITO, L. T. L.. Implicações das secas para agricultura de subsistência e a alternativa no semiárido do Nordeste brasileiro. In: EMBRAPA SEMIÁRIDO-ARTIGO EM ANAIS DE CONGRESSO; CONGRESSO BRASILEIRO DE ECONOMIA E SOCIOLOGIA RURAL, 34. Anais. Brasília: SOBER, 1996. p.294-309.

IBGE. Instituto Brasileiro de Geografia e Estatística. Dados shape file 2015. IBGE, 2015.

IBGE. Instituto Brasileiro de Geografia e Estatística. Cidades: Sousa, Censo 2010. IBGE, 2010.

MARENGO, J. A.. Vulnerabilidade, impactos e adaptação à mudança do clima no semiárido do Brasil. Parcerias estratégicas, v.13, n.27, p.149-176, 2010.

NYS, E.; ENGLE, N, L.; MAGALHÃES, A. R.. Secas no Brasil: Política e gestão proativa. 2016.

SIQUEIRA, E. C.; SEMIRAMES N. S.; LOPES, F. G.; AMDRADE, F. E.; FERREIRA, C. B.; DANTAS, M. C. A. M.. Efeitos da escassez hídrica na economia do perímetro irrigado de São Gonçalo, Paraíba. Revista Verde de Agroecologia e Desenvolvimento Sustentável, v.12, n.1, p.132-137, 2017. 
SILVA, B. B.; BRAGA, A. C.; BRAGA, C. C.; OLIVEIRA, L. M. M.; GALVÍNCIO, J. D.; MONTENEGRO, S. M. G. L..

Evapotranspiração e estimativa da água consumida em perímetro irrigado do Semiárido brasileiro por sensoriamento remoto. Pesquisa Agropecuária Brasileira, v.47, n.9, p.1218-1226, 2012.
SILVA, V. M. A.; PATRÍCIO, M. C. M.; RIBEIRO V. H. A.; MEDEIROS, R. M.. O desastre seca no Nordeste Brasileiro. POLÊM!CA, v.12, n.2, p.284-293, 2013.

SUASSUNA, J.. Semiárido: proposta de convivência com a seca. Cadernos de Estudos Sociais, v.23, p.3, 2007.

A CBPC - Companhia Brasileira de Produção Científica (CNPJ: 11.221.422/0001-03) detém os direitos materiais desta publicação. Os direitos referem-se à publicação do trabalho em qualquer parte do mundo, incluindo os direitos às renovações, expansões e disseminações da contribuição, bem como outros direitos subsidiários. Todos os trabalhos publicados eletronicamente poderão posteriormente ser publicados em coletâneas impressas sob coordenação da Sustenere Publishing, da Companhia Brasileira de Produção Científica e seus parceiros autorizados. Os (as) autores (as) preservam os direitos autorais, mas não têm permissão para a publicação da contribuição em outro meio, impresso ou digital, em português ou em tradução. 